\title{
Overexpression of caudal type homeobox transcription factor 2 inhibits the growth of the MGC-803 human gastric cancer cell line in vivo
}

\author{
WEIYUAN WEI $^{*}$, LEI LI ${ }^{2 *}$, XIAOTONG WANG ${ }^{2 *}$, LINHAI YAN $^{1}$, WENLONG CAO $^{1}$, \\ ZEXU ZHAN ${ }^{1}$, XIAOSHI ZHANG ${ }^{1}$, HAN YU $^{1}$, YUBO XIE $^{3}$ and QIANG XIAO ${ }^{1}$ \\ ${ }^{1}$ Department of Surgery, The First Affiliated Hospital of Guangxi Medical University; ${ }^{2}$ Department of Surgery, \\ People's Hospital of Guangxi Zhuang Autonomous Region; ${ }^{3}$ Department of Anesthesiology, \\ The First Affiliated Hospital of Guangxi Medical University, Nanning, Guangxi 530021, P.R. China
}

Received July 14, 2014; Accepted February 11, 2015

DOI: $10.3892 / \mathrm{mmr} .2015 .3413$

\begin{abstract}
Caudal type homeobox transcription factor 2 (CDX2) is important in intestinal cell fate specification and multiple lines of evidence have substantiated that CDX2 is important in carcinogenesis of the digestive tract. The CDX2 regulatory network is intricate and remains to be fully elucidated in gastric cancer. The aim of the present study was to examine the effects of CDX2 on the growth of the MGC-803 human gastric cancer cell line in vivo, and to elucidate the mechanism involved. The effects of the overexpression of CDX2 in xenograft tumors of MGC-803 cells was investigated in nude mice through the injection of CDX2 recombinant lentiviral vectors. The tumor size was measured using vernier callipers. The expression levels of CDX2, survivin, B-cell lymphoma 2 (Bcl-2), Bcl-2-associated X protein (Bax), cyclin D1, s-phase kinase-associated protein 2 (Skp2) and $\mathrm{c}-\mathrm{Myc}$ in the tumor cells were analyzed by western blotting and semi-quantitative reverse transcription polymerase chain reaction. The apoptotic rates were determined using a terminal deoxynucleotidyl transferase-mediated dUTP-biotin nick end labeling assay. The overexpression of CDX2 was observed in the group subjected to the injection of CDX2 recombinant lentiviral vectors. CDX2 had an inhibitory effect on the
\end{abstract}

Correspondence to: Professor Qiang Xiao, Department of Surgery, The First Affiliated Hospital of Guangxi Medical University, No. 6 Shuang-yong Road, Nanning, Guangxi 530021, P.R. China

E-mail: xiaoqiang20050@aliyun.com.cn

Professor Yubo Xie, Department of Anesthesiology, The First Affiliated Hospital of Guangxi Medical University, No. 6 Shuang-yong Road, Nanning, Guangxi 530021, P.R. China

E-mail: xieyubo715001@aliyun.com

*Contributed equally

Key words: caudal type homeobox transcription factor 2, gastric cancer, nude mice model, nuclear factor- $\kappa \mathrm{B}$ pathway
MGC-803 human gastric cancer cell line and promoted tumor cell apoptosis in vivo. Furthermore, the overexpression of CDX2 upregulated the expression of Bax and downregulated the expression levels of survivin, Bcl-2, cyclin D1, Skp2 and c-Myc in the tumor tissues. These results indicated that CDX2 may serve as a tumor suppressor in gastric cancer, and inhibits gastric cancer cell growth by suppressing the nuclear factor- $\mathrm{kB}$ signaling pathway.

\section{Introduction}

Gastric cancer is among the most common type of cancer worldwide and is currently the third most common type of cancer, although the incidence is decreasing (1). Despite novel treatment strategies, including perioperative chemotherapy and adjuvant chemoradiation using external radiotherapy, gastric cancer is usually diagnosed at an advanced stage and the prognosis remains poor (2). Thus, an improved understanding of the molecular events involved in the development and progression of gastric cancer may lead to novel treatment methods with improved efficacy.

Caudal type homeobox transcription factor 2 (CDX2) is a member of the Cdx gene family and is an intestine-specific homeobox transcription factor, which is highly expressed in the intestinal epithelium of adult animals, where it is responsible for directing the differentiation of intestinal epithelial cells $(3,4)$. Importantly, CDX2 is associated with the development of intestinal metaplasia of the stomach and with gastric carcinogenesis $(5,6)$. Certain studies have demonstrated that there are significant correlations between CDX2 and intestinal-type adenocarcinoma $(7,8)$. In addition, a previous biological study demonstrated that CDX2 may be important in gastric tumorigenesis (9), whereas another study suggested that CDX2 is a tumor suppressor (10).

To the best of our knowledge, no comprehensive studies have been performed to assess the overexpression of CDX2 in gastric cancer. In our previous study, the overexpression of CDX2 exhibited a significant effect on cell growth and proliferation in an in vitro cell model of gastric cancer (11). However, the molecular mechanisms underlying the overexpression 
of CDX2, which inhibit cell growth and increase the levels of apoptosis remain to be fully elucidated. The aim of the present study was to evaluate the effects of the overepxression of CDX2 on the growth and level of apoptosis in MGC-803 cells in vivo by administering nude mice with intratumoral injections of a recombinant $\mathrm{CDX} 2$ lentivirus. In addition, to reveal the possible underlying mechanisms, the effects of the overexpression of CDX2 on the mRNA and protein expression levels of B-cell lymphoma 2 (Bcl-2), Bcl-2-associated X protein (Bax), survivin, cyclin D1, S-phase kinase-associated protein 2 (Skp2) and c-Myc were examined in MGC-803 cells in vivo.

\section{Materials and methods}

Antibodies. Specific rabbit anti-human polyclonal antibodies to CDX2 (\#12306), c-Myc (\#5605), Skp2 (\#2652), Bax (\#5023), Bcl-2 (\#2827), cyclin D1 (\#2978), survivin (\#2808) and GAPDH (\#2118) were provided by Cell Signaling Technology, Inc. (Beverly, MA, USA). Infrared-labeled secondary goat anti-rabbit antibodies to IRDye 800 were obtained from Li-Cor Biosciences (Lincoln, NE, USA). All the above antibodies were used by diluted 1000 times in western blot analysis.

Cell culture. The MGC-803 human gastric carcinoma cell line and 293T human embryonic kidney cells were provided by the Cell Bank of Shanghai Institute of Cell Biology, Chinese Academy of Sciences (Shanghai, China). The cells were maintained at $37^{\circ} \mathrm{C}$ in an atmosphere containing $5 \% \mathrm{CO}_{2}$ in Dulbecco's modified Eagle's Medium, supplemented with $10 \%$ fetal bovine serum, $100 \mathrm{U} / \mathrm{ml}$ penicillin and $100 \mu \mathrm{g} / \mathrm{ml}$ streptomycin.

Construction of the CDX2 recombinant lentiviral vectors. The lentivitus overexpressing the CDX2 gene was constructed at Shanghai Genechem Co., Ltd. (Shanghai, China). The lentiviral vector system consisted of a GV208, pHelper 1.0 vector and pHelper 2.0 vector prior to packaging and was provided by Shanghai Genechem Co., Ltd. (Shanghai, China). The full length of the human CDX2 gene (NCBI ID, NM_001265.4), which was indicated by enhanced green fluorescent protein (GFP), which was encoded into the GV208 vector. The three vectors were cotransfected into $293 \mathrm{~T}$ cells $\left(3 \times 10^{4} / \mathrm{ml}\right)$ in serum-free medium using Lipofectamine 2000 (Invitrogen Life Technologies, Carlsbad, CA, USA). The medium was replaced with complete medium following $8 \mathrm{~h}$ incubation at $37^{\circ} \mathrm{C}$. The high-titer recombinant lentiviral vectors carrying CDX2 were harvested $48 \mathrm{~h}$ following transfection.

Xenograft tumor model. The animals used in the present study were BALB/c nude male mice (4 weeks old), which were purchased from Guangxi Animal Center (Nanning, China). The number of nude mice was six in each group, weighing between 20 and $24 \mathrm{~g}$, and they were fed under specific pathogen-free conditions. All procedures were in accordance with the National Institutes of Health Guide for the Care and Use of Laboratory Animals (National Institutes of Health, Bethesda, MD, USA). Tumors were established in the mice via a single subcutaneous injection of $4 \times 10^{7} \mathrm{MGC}-803$ cells into the armpit region. The study was approved by the ethics committee of the First Affiliated Hospital of Guangxi Medical University, (Guangxi, China).

Treatment of the MGC-803 tumor in nude mice. When the tumors had reached a diameter of $\sim 5 \mathrm{~mm}$, the mice were randomized into three groups: Lentivirus (LV)-GFP-CDX2, LV-GFP-negative control (NC) and phosphate-buffered saline (PBS; Beyotime Institute of Biotechnology, Shanghai, China). Each group contained eight mice $(n=8)$. The animals were administered with an intratumoral injection of either the LV-GFP-CDX2 or LV-GFP-NC at a titer of $10^{8}$ transducing units in $100 \mu \mathrm{l}$ PBS, while the control group of mice received an equal volume of PBS. Subsequent to the first injection, the animals were administered with a similar injection every 2 days. The mouse body weight, the quantity of water and food intake, vital signs and living status were assessed daily. The tumor volume was measured and calculated as follows: The longer diameter, 'a', and the shortest diameter, ' $b$ ', of the tumors were measured using digital calipers, and the tumor volume (TV) was calculated using the following equation: $\mathrm{TV}=\mathrm{a} \times \mathrm{b}^{2} / 2$. The relative tumor volume (RTV) was calculated using the formula: $R T V=V_{t} / V_{0}$, in which $V_{0}$ is the TV on the day when the treatment was administered, and $V_{t}$ is the TV of the subsequent measurement. Following the tumor cell injections (15 days), the animals were sacrificed by cervical dislocation and the tumors were then analyzed.

Reverse transcription semi-quantitative-polymerase chain reaction ( $R T$-sqPCR). The total RNA was extracted from the tumor tissues using TRIzol reagent (Sigma-Aldrich, St. Louis, MO, USA), according to the manufacturer's instructions. cDNA was generated from a DNase-1-treated RNA template with $0.2 \mu \mathrm{g}$ random hexamer primers (Takara Bio, Inc., Tokyo, Japan) and 200 units RevertAid H-Minus M-MuLV reverse transcriptase enzyme (Roche, Basel, Switzerland). The primer sequences used to specifically amplify the genes of interest are shown in Table I. The cDNA $(2 \mu \mathrm{l})$ produced was added to $10 \mu 1$ Taq Premix and the upstream and downstream primers (1 $\mu 1$ each). RT-qPCR was performed as follows: 1 cycle at $94^{\circ} \mathrm{C}$ for $5 \mathrm{~min}, 30$ cycles at $94^{\circ} \mathrm{C}$ for $30 \mathrm{sec}$ for denaturation, $56^{\circ} \mathrm{C}$ for $30 \mathrm{sec}$ for annealing, $68^{\circ} \mathrm{C}$ for $45 \mathrm{sec}$ for extension and 1 cycle $5 \mathrm{~min}$ at $72^{\circ} \mathrm{C}$, according to the RT-qPCR amplification kit (Takara Bio, Inc.) manufacturer's instructions. The amplified PCR products were run on $1.5 \%$ agarose gels and visualized under UV light following ethidium bromide $(0.5 \mu \mathrm{g} / \mathrm{ml}$; Beyotime Institute of Biotechnology) staining at room temperature $\left(25^{\circ} \mathrm{C}\right)$ for $20 \mathrm{~min}$.

Western blot analysis. The tumor tissues were homogenized for tissue lysate extraction, the tissue lysates were centrifuged and the supernatants were collected. Equal quantities $(150 \mu \mathrm{g})$ of protein were heated to $100^{\circ} \mathrm{C}$ for 5 min with Laemmli sample buffer (Beyotime Institute of Biotechnology), then separated on 12\% SDS-PAGE gels (Beyotime Institute of Biotechnology) and transferred onto polyvinylidene difluoride membranes. The entire process was performed using Bio-Rad equipment (Bio-Rad Laboratories, Inc., Hercules, CA, USA) according to the manufacturer's instructions. The membrane was probed with the primary antibody $(1: 1,000)$ and incubated overnight at $4^{\circ} \mathrm{C}$. The blots were washed three times in PBS 
Table I. Sequences of the primers used for reverse transcription semi-quantitative polymerase chain reaction.

\begin{tabular}{|c|c|c|c|}
\hline Gene & Primer & Sequence & PCR product (bp) \\
\hline CDX2 & $\begin{array}{l}\text { Forward } \\
\text { Reverse }\end{array}$ & $\begin{array}{l}\text { 5'- CGGCAGCCAAGTGAAAAC-3' } \\
\text { 5'-GATGGTGATGTAGCGACTGTAGTG-3' }\end{array}$ & 217 \\
\hline Survivin & $\begin{array}{l}\text { Forward } \\
\text { Reverse }\end{array}$ & $\begin{array}{l}\text { 5'-AAATGCACTCCAGCCTCTGT-3' } \\
\text { 5'-TGTCGAGGAAGCTTTCAGGT-3' }\end{array}$ & 311 \\
\hline $\operatorname{Bax}$ & $\begin{array}{l}\text { Forward } \\
\text { Reverse }\end{array}$ & $\begin{array}{l}\text { 5'-CCAAGAAGCTGAGCGAGTGT-3' } \\
\text { 5'-CCGGAGGAAGTCCAATGTC-3' }\end{array}$ & 269 \\
\hline $\mathrm{Bcl}-2$ & $\begin{array}{l}\text { Forward } \\
\text { Reverse }\end{array}$ & $\begin{array}{l}\text { 5'-GACTTCGCCGAGATGTCCAG-3' } \\
\text { 5'-CATCCCAGCCTCCGTTATCC-3' }\end{array}$ & 259 \\
\hline Cyclin D1 & $\begin{array}{l}\text { Forward } \\
\text { Reverse }\end{array}$ & $\begin{array}{l}\text { 5'-CCCTCGGTGTCCTACTTCAA-3' } \\
\text { 5'-GGGGATGGTCTCCTTCATCT-3' }\end{array}$ & 237 \\
\hline Skp2 & $\begin{array}{l}\text { Forward } \\
\text { Reverse }\end{array}$ & $\begin{array}{l}\text { 5'-GCTGCTAAAGGTCTCTGGTGT-3' } \\
\text { 5'-AGGCTTAGATTCTGCAACTTG-3' }\end{array}$ & 291 \\
\hline C-Myc & $\begin{array}{l}\text { Forward } \\
\text { Reverse }\end{array}$ & $\begin{array}{l}\text { 5'-TTCTCTCCGTCCTCGGATTC-3' } \\
\text { 5'-GTAGTTGTGCTGATGTGTGG-3' }\end{array}$ & 282 \\
\hline GAPDH & $\begin{array}{l}\text { Forward } \\
\text { Reverse }\end{array}$ & $\begin{array}{l}\text { 5'-ACCACAGTCCATGCCATCAC-3' } \\
\text { 5'-TCACCACCCTGTTGCTGTA-3' }\end{array}$ & 450 \\
\hline
\end{tabular}

Bcl-2, B-cell lymphoma 2; CDX2, caudal type homeobox transcription factor 2; Bax, Bcl-2-associated X protein; Skp2, S-phase kinase-associated protein 2 .

with Tween 20 prior to incubation with species-appropriate, peroxidase-conjugated secondary antibodies for $1 \mathrm{~h}$. The blots were then washed again three times in PBS with Tween 20. The net intensities of the bands were quantified using Odyssey software version 3.0 (Li-Cor Biosciences, Lincoln, NE, USA).

In situ analysis of MGC-803 tumor cell apoptosis using a terminal deoxynucleotidyl transferase-mediated dUTP-biotin nick end labeling (TUNEL) assay. Tissue samples were fixed in $4 \%$ buffered paraformaldehyde at $4^{\circ} \mathrm{C}$ for $48 \mathrm{~h}$ and then processed for paraffin embedding. The procedures of paraffin embedding were dehydration and waxdip. Paraffin-embedded (Beyotime Institute of Biotechnology) sections were prepared for hematoxylin and eosin (Beyotime Institute of Biotechnology) staining. The levels of tumor tissue necrosis were determined by comparing the surface of necrotic areas with that of the whole tumor. Levels of apoptosis were determined using a TUNEL assay kit, according to the manufacturer's instructions. Briefly, the cells were rinsed with PBS twice for $3 \mathrm{~min}$, prior to the addition of $50 \mu 1$ TUNEL cocktail on test sections. Labeling solution (40 $\mu \mathrm{l}$ ) was added to control sections on one slide and PBS was added to the control sections on other slides, and incubated in a humidified chamber for $60 \mathrm{~min}$ at $37^{\circ} \mathrm{C}$ in the dark. A sample was considered positive when it contained 25 positively stained cells in every 100 tumor cells, which was calculated from five randomly selected fields for each specimen. The stained tissue sections were visualized by microscopy (CP-111-2; magnification, x400; Jenco International, Protland, OR, USA).

Statistical analysis. Data are expressed as the mean \pm standard error of the mean and were analyzed using SPSS version 13.0 (SPSS, Inc., Chicago, IL, USA). One-way analysis of variance was used to measure statistical significance among groups, followed by the Student-Newman-Keuls test. $\mathrm{P}<0.05$ was considered to indicate a statistically significant difference.

\section{Results}

Construction and identification of p GCL-GFP-CDX2 lentiviral vectors. The positive clones were confirmed by DNA sequence analysis (data not shown) and it was demonstrated that the RNA coding frames and frame sequences were correct and that the recombinant pGCL-GFP-CDX2 and pGCL-GFP-NC plasmids had been constructed successfully.

Determination of lentiviral titers. A lentivirus targeting CDX2 and an NC vector (LV-GFP-CDX2, and LV-GFP-NC, respectively) were produced by co-transfection with a packaging vector (pHelper1.0) and a vesicular stomatitis virus glycoprotein expression plasmid (pHelper2.0) into the 293T cells. As shown in Fig. 1, the GFP-labeling results indicated that the lentiviral vectors were suitably transfected for use in the present study.

Overexpression of CDX2 inhibits MGC-803 tumor growth. As shown in Fig. 2A, the tumor growth curves indicated that mice treated with LV-GFP-CDX2 exhibited significant inhibition of tumor growth when compared with those treated with the LV-GFP-NC control vector or PBS $(\mathrm{P}<0.05)$. The tumor volumes in the mice in the LV-GFP-CDX2 group were significantly smaller compared with those of the control groups $(\mathrm{P}<0.05)$ at 15 days post-tumor injection, whereas no difference was identified between the Lv-GFP-NC and PBS groups $(\mathrm{P}>0.05$; Fig. 2B). These results indicated that overexpression of CDX2 effectively inhibited MGC-803 tumor growth in vivo. 

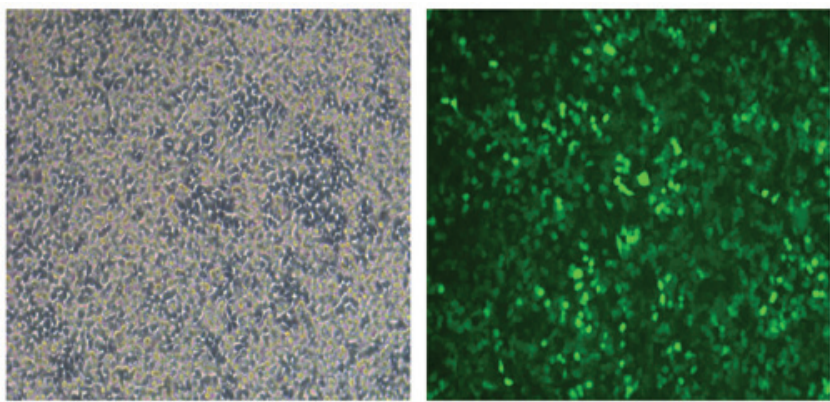

LV-GFP-CDX2
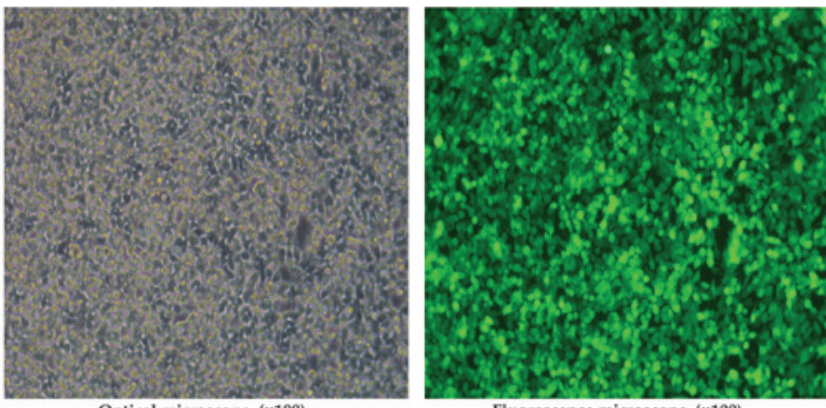

Optical microscope $(\times 100)$

Fluorescence microscope $(\times 100)$

Figure 1. Determination of lentivirus titers. The viral titers of recombinant lentivirus transfected into 293T cells were determined by end point dilution, through counting the numbers of fluorescent green-labeled cells under a fluorescence microscope (magnification, x100). The viral dilution factor was 1:1,000. LV-GFP, lentivirus-green fluorescent protein; NC, negative control; CDX2, caudal type homeobox transcription factor 2.

A

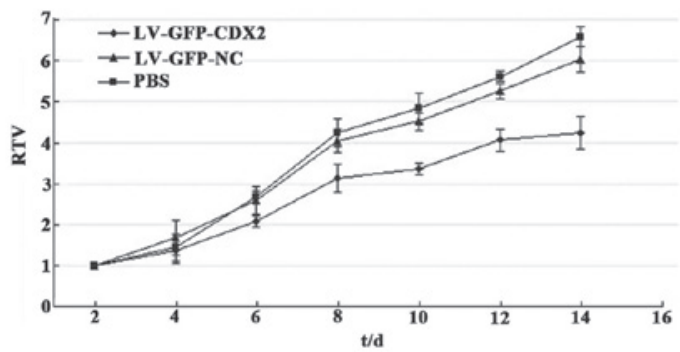

B

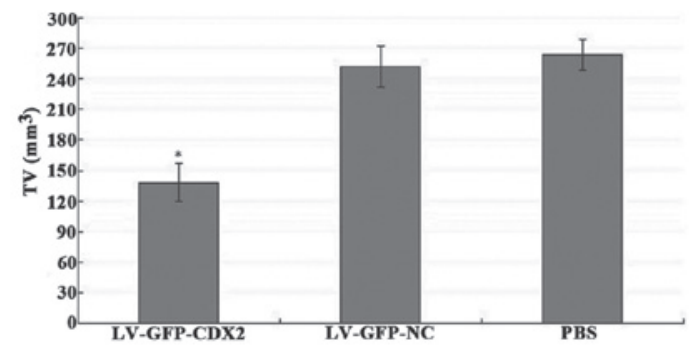

C
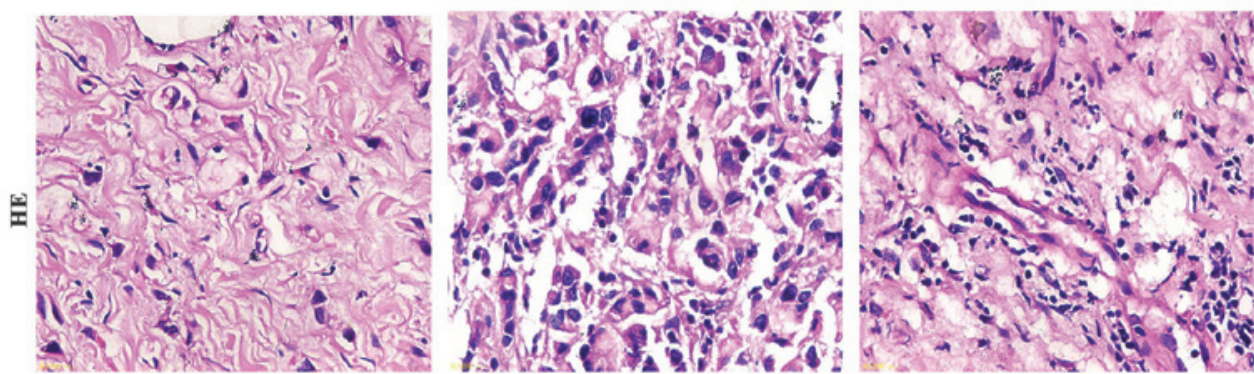

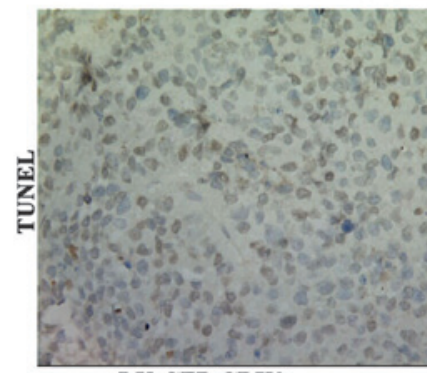

LV-GFP-CDX2

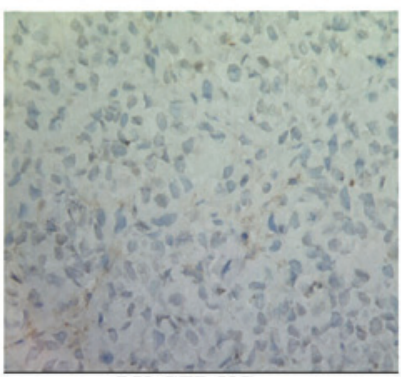

LV-GFP-NC

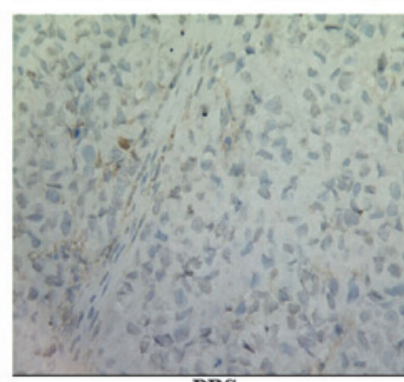

PBS

Figure 2. Overexpression of CDX2 inhibits tumor growth and induces tumor cell apoptosis in LV-GFP-CDX2-treated mice. (A) Relative tumor volume growth curve revealed significant growth tendencies in the PBS and LV-GFP-NC groups, while the MGC-803 tumor growth in the LV-GFP-CDX2 group was markedly inhibited. (B) Tumor volumes in the LV-GFP-CDX2 groupe were smaller compared with those in the control group 14 days after tumor injection $\left({ }^{*} \mathrm{P}<0.05\right)$. (C) Tumor cell apoptosis was assessed using a TUNEL assay and HE staining, revealing that the MGC-803 tumor cells in the LV-GFP-CDX2 group had higher levels of apoptosis compared with the LV-GFP-NC and PBS groups (magnification, x400). CDX2, vaudal type homeobox transcription factor 2; LV-GFP, lentivirus-green fluoresent protein; PBS, phosphate-buffered saline; NC, negative control; TV, tumor volume; RTV, relative TV; TUNEL, terminal deoxynucleotidyl transferase-mediated dUTP-biotin nick end labeling; HE, hematoxylin and eosin. 
A

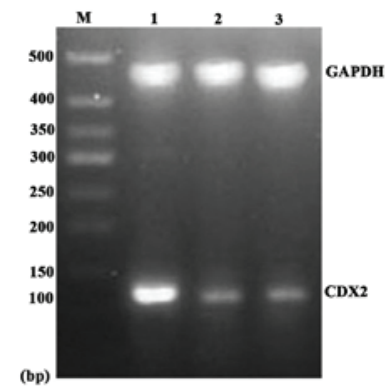

C

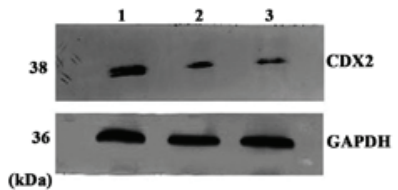

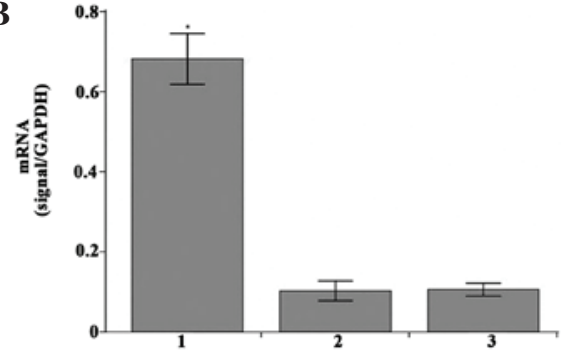

D

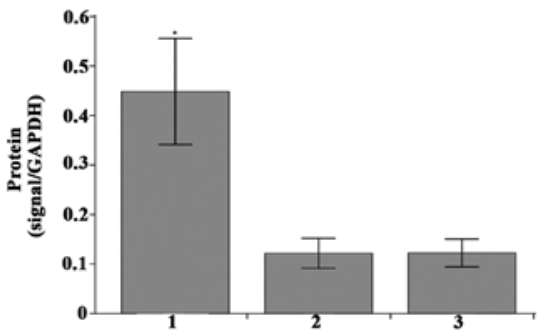

Figure 3. Overexpression of CDX2 mRNA and protein in the LV-GFP-CDX2 group. (A) Reverse transcription semi-quantitative polymerase chain reaction analysis of CDX2 and GAPDH in the MGC-803 tumor tissues from the LV-GFP-CDX2, LV-GFP-NC and PBS groups. M, 500 bp marker. (B) mRNA expression levels of CDX2 were measured in the three groups, normalized to GAPDH and presented as the mean \pm standard error of the mean (n=8 in each group). (C) Western blot analysis of the protein expression levels of CDX2 and GAPDH in the MGC-803 tumor tissues from the three groups. (D) Protein expression levels of CDX2 were measured in the three groups, normalized to GAPDH and presented as the mean \pm standard error of the mean ( $\mathrm{n}=8$ in each group). Lanes: 1, LV-GFP-CDX2 group; 2, LV-GFP-NC group; 3, PBS group, GAPDH: internal control mRNA and protein..P $<0.05$ compared with LV-GFP-NC and PBS group, using analysis of variance and Student-Newman-Keuls analyses. CDX2, caudal type homeobox transcription factor 2; LV-GFP, lentivirus-green fluoresent protein; PBS, phosphate-buffered saline; NC, negative control.
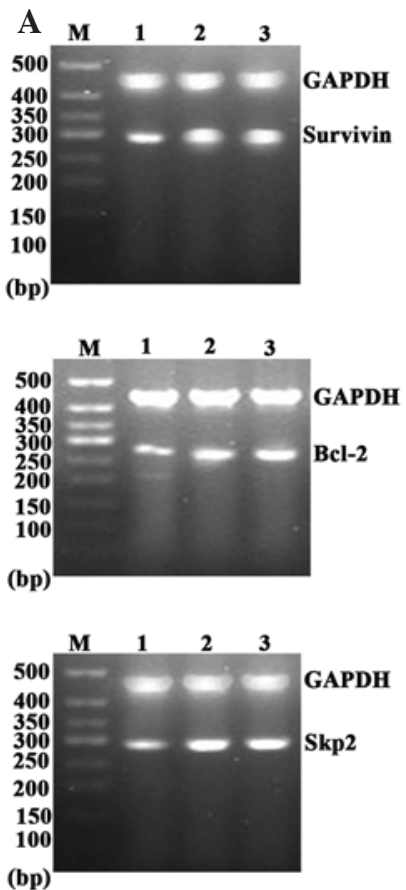
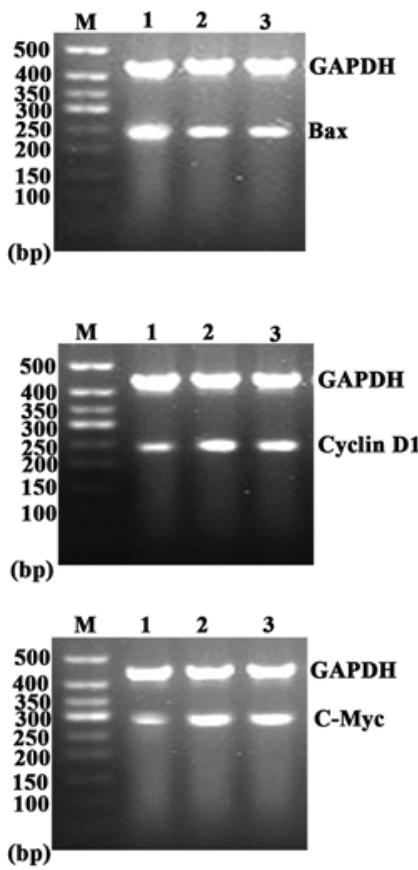

B

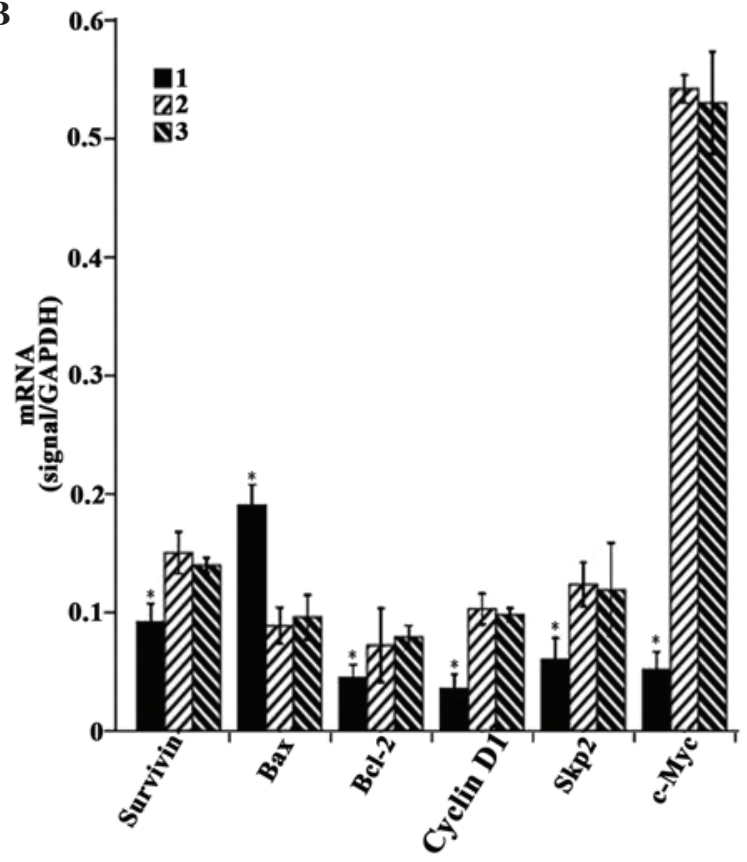

Figure 4. Overexpression of CDX2 induces downregulation in the mRNA expression levels of c-Myc, Skp2, Bcl-2, cyclin D1 and survivin and upregulation in the expression of Bax. (A) Reverse transcription semi-quantitative polymerase chain reaction analysis of c-Myc, Skp2, Bcl-2, cyclin D1, survivin, Bax and GAPDH in the MGC-803 tumor tissues from the LV-GFP-CDX2, 2, LV-GFP-NC and PBS groups. M, 500 bp marker (B) mRNA expression levels of c-Myc, Skp2, Bcl-2, cyclinD1, survivin and Bax were measured in the three groups, normalized to those of GAPDH and presented as the mean \pm standard error of the mean ( $\mathrm{n}=8$ in each group). 1, LV-GFP-CDX2 group; 2, LV-GFP-NC group; 3, PBS group; GAPDH: internal control. " $\mathrm{P}<0.05$, compared with the LV-GFP-NC and PBS groups, using analysis of variance and Student-Newman-Keuls analyses. Bcl-2, B-cell lymphoma 2; Bax, Bcl-2-associated X protein; Skp2, S-phase kinase-associated protein 2; CDX2, caudal type homeobox transcription factor 2; LV-GFP, lentivirus-green fluoresent protein; PBS, phosphate-buffered saline.

Overexpression of CDX2 induces MGC-803 tumor cell apoptosis. As shown in Fig. 2C, the percentage of apoptotic tumor cells in the LV-CDX2-GFP group was $17.32 \pm 2.5 \%$, which was significantly higher compared with that observed in the LV-GFP-NC $(7.2 \pm 1.7 \%)$ and PBS $(6.6 \pm 1.8 \%)$ groups, demonstrated using the TUNEL method $(\mathrm{P}<0.05)$. These results 

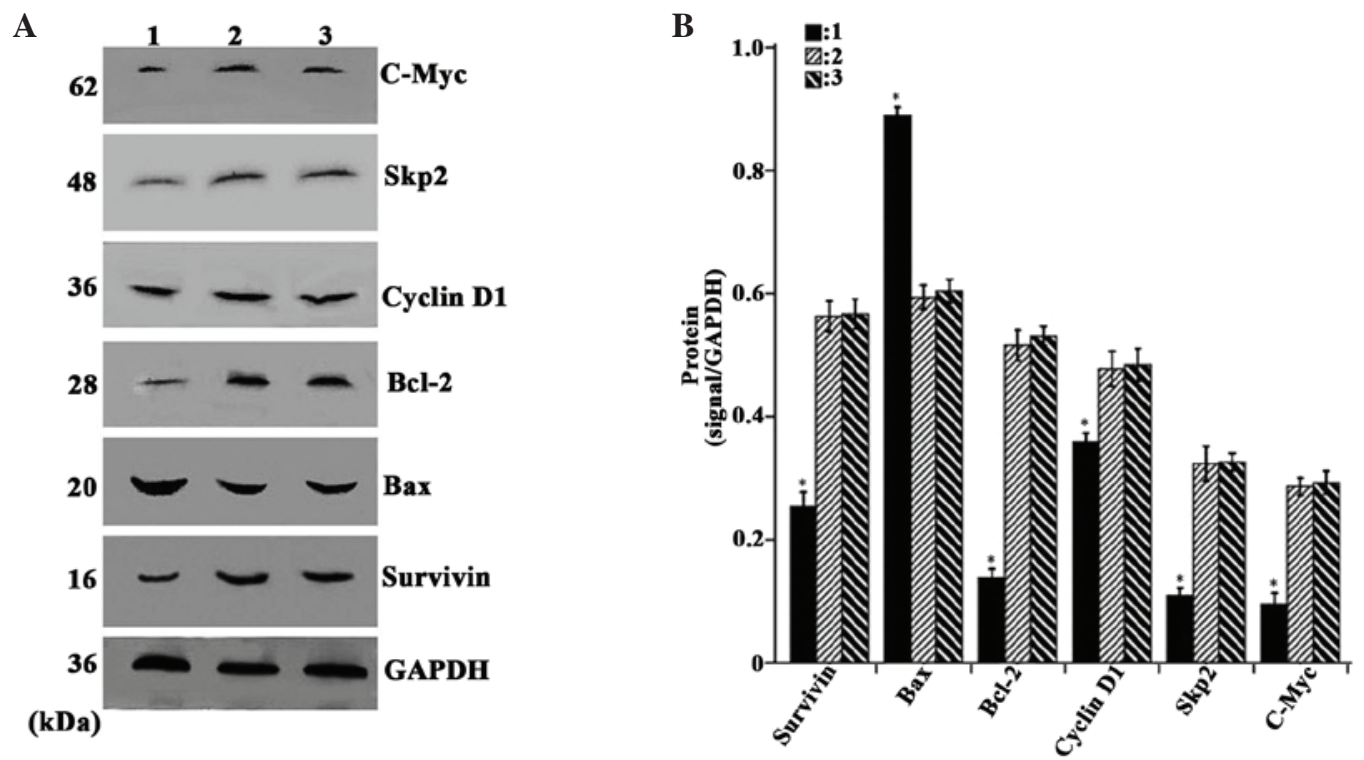

Figure 5. Overexpression of CDX2 induces downregulation of the protein expression levels of c-Myc, Skp2, Bcl-2, cyclinD1 and survivin and upregulation of Bax. (A) Western blot analysis of c-Myc, Skp2, Bcl-2, cyclin D1, survivin, Bax and GAPDH in the MGC-803 tumor tissue from the LV-GFP-CDX2, LV-GFP-NC and PBS groups. (B) Protein expression levels of c-Myc, Skp2, Bcl-2, cyclin D1, survivin and Bax were measured in the three groups, normalized to those of GAPDH and expressed as the mean \pm standard error of the mean ( $\mathrm{n}=8$ in each group). 1, LV-GFP-CDX2 group; 2, LV-GFP-NC group; 3 , PBS group; GAPDH: internal control. "P $<0.05$, compared with the LV-GFP-NC and PBS group, using analysis of variance and Student-Newman-Keuls analyses. Bcl-2, B-cell lymphoma 2; Bax, Bcl-2-associated X protein; Skp2, S-phase kinase-associated protein 2; CDX2, caudal type homeobox transcription factor 2; LV-GFP, lentivirus-green fluoresenct protein; PBS, phosphate-buffered saline.

suggested that overexpression of CDX2 effectively promoted MGC-803 tumor cell apoptosis in vivo.

$m R N A$ and protein expression levels of CDX2 are increased in MGC-803 tumor tissues. Densitometric analysis revealed that mRNA and protein expression levels of CDX2 in the LV-GFP-CDX2 group were higher compared with those of the two control groups $(\mathrm{P}<0.05$; Fig. 3A-D). These results suggested that the nude mouse model overexpressing CDX2 had been constructed successfully by injection with the CDX2 recombinant lentiviral vectors.

Overexpression of CDX2 decreases the expression levels of c-Myc, Skp2, Bcl-2, cyclin D1 and survivin, and increases the expression of Bax. As shown in Fig. $4 \mathrm{~A}$ and B, the densitometric analysis revealed that the mRNA expression levels of c-Myc, Skp2, Bcl-2, cyclin D1 and survivin in the LV-GFP-CDX2 group were lower, while the expression of Bax was higher compared with the LV-GFP-NC and PBS groups $(\mathrm{P}<0.05)$. In addition, as shown in Fig. $5 \mathrm{~A}$ and $\mathrm{B}$, the densitometry revealed that the protein expression levels of c-Myc, Skp2, Bcl-2, cyclin D1 and survivin in the LV-GFP-CDX2 group was lower, that of while Bax was higher compared with the LV-GFP-and PBS groups $(\mathrm{P}<0.05)$. These results suggested that the overexpression of CDX2 effectively decreased the expression levels of c-Myc, Skp2, Bcl-2, cyclin D1, survivin, and increased the expression of Bax in the MGC-803 tumor cells in vivo.

\section{Discussion}

CDX2 is a nuclear transcription factor, which is important in embryologic development and in the differentiation of the intestinal tract epithelium (12). It is also highly expressed in epithelial tumors of the gastrointestinal tract (13) and, for this reason, its role in tumorigenesis has become an important area of investigation. Although several lines of evidence have indicated that CDX2 is a potential tumor suppressor gene in ovarian, gallbladder, colon and gastric cancer $(12,14-17)$, the mechanisms associating the overexpression of CDX2 with gastric cancer remain to be elucidated.

In the present study, a marked antitumoral effect of the overexpression of CDX2 on MGC-803 cells was observed in vivo. Tumor growth was suppressed and tumor apoptosis was increased in nude mice when the CDX2 mRNA and protein were overexpressed via lentiviral vector-mediated overexpression of CDX2. These findings were concordant with our previous study, which observed that the overexpression of CDX2 inhibits the progression of gastric cancer in vitro $(11,18)$. Therefore, lentiviral vector-mediated overexpression of CDX2 may be used as a potent and specific therapeutic tool for the treatment of gastric cancer. In addition, the present study revealed that overexpression of $\mathrm{CDX} 2$ decreased the expression levels of survivin, Bcl-2, cyclin D1, Skp2 and c-Myc, and increased the expression of Bax.

Previous studies have confirmed that the Bax, Bcl-2, cyclin D1, c-Myc, Skp2 and survivin genes are associated with cell proliferation, cell apoptosis and tumor development (19-22). Takahashi et al (23) suggested that CDX2 inhibited the gene expression of exogenous nuclear factor (NF)- $\kappa \mathrm{B}$-induced luciferase in a dose-dependent manner. Furthermore, Yang et al (24) and Saha et al (25) demonstrated that NF- $\kappa \mathrm{B}$ induces the expression of genes involved in cell proliferation (cyclin D1 and c-Myc) and anti-apoptotic (survivin and Bcl-2), while it inhibits the expression of the pro-apoptotic gene, Bax. In addition, the NF- $\kappa \mathrm{B}$ signaling pathway regulates the cell cycle by binding of the NF- $\mathrm{B}$ subunits to the cyclin D1, 
c-Myc and Skp2 promoters, which are concomitant with a switch from coactivator to corepressor recruitment (26). This suggests that the overexpression of CDX2 may directly or indirectly modulate the transcriptional activity of downstream genes (Bax, Bcl-2, cyclin D1, Skp2, c-Myc and survivin) by inhibiting the gene expression of $\mathrm{NF}-\kappa \mathrm{B}$.

Downregulation of the $\mathrm{NF}-\kappa \mathrm{B}$ signaling pathway induces downregulation of the anti-apoptotic gene, Bcl-2 and upregulation of the pro-apoptotic gene, Bax (27). The Bcl-2 family of proteins represent essential targets in cancer therapy (28). The Bax, Bcl-2 homologous antagonist killer and Bcl-2 related ovarian killer pro-apoptotic and Bcl-2, Bcl-extra large and myeloid cell leukemia 1 anti-apoptotic members of the $\mathrm{Bcl}-2$ family may promote or inhibit apoptosis through the formation of heterodimers among these proteins (29). Therefore, the ratio between the pro-apoptotic $\mathrm{Bax}$ and anti-apoptotic $\mathrm{Bcl}-2$ proteins is an important determinant of cell survival and death. In the present study, upregulation of the pro-apoptotic protein, Bax and downregulation of the anti-apoptotic protein, Bcl-2 were observed in the LV-CDX2-GFP group, and gray scale value analysis revealed a significantly higher $\mathrm{Bax} / \mathrm{Bcl}-2$ ratio in the treatment group compared with the untreated controls. A higher Bax/Bcl-2 ratio has been reported to be a cause of cell death (30). This suggests that the overexpression of CDX2 induced apoptosis by altering the $\mathrm{Bax} / \mathrm{Bcl}-2$ ratio to suppress gastric cancer growth.

Barré et al (26) observed that $\mathrm{NF}-\kappa \mathrm{B}$ subunits regulate the gene expression of the cyclin D1, c-Myc and Skp2, and downregulation of $N F-\kappa B$ can result in a change in the function of the $\mathrm{NF}-\kappa \mathrm{B}-\mathrm{binding}$ site, resulting in repression of the cyclin D1, c-Myc and Skp2 gene promoter. Cyclin D1, c-Myc and Skp2 are cell cycle regulators, and the cell cycle is arrested through suppression of the expression of cyclin D1, c-Myc and Skp2 (31-33). Therefore, the overexpression of CDX2 may also suppress the cell cycle through the indirect suppression of the expression of cyclin D1, c-Myc and Skp2 through the NF- $\mathrm{B}$ signaling pathway. In addition, cell immortalization is a basic step in tumor growth (34). Therefore, control of the cell cycle may be an important mechanism in the suppression of tumor growth by CDX2 in gastric cancer.

A previous study demonstrated that survivin is downregulated via the $\mathrm{NF}-\kappa \mathrm{B}$-mediated signaling pathway, thus inhibiting the growth of cancer cells (35). Survivin is an important factor in cell division, and the separation of chromatin in mitosis may be faulty in cancer cells lacking expression of the survivin gene $(36,37)$. The cell cycle checkpoint mechanism activates following mitotic dysfunction, which promotes apoptosis in abnormal cells (38). The present study demonstrated that the overexpression of CDX2 significantly inhibited the growth of transplanted tumors and promoted cell apoptosis, which may be attributed to the indirect downregulation of survivin by CDX2, by inhibiting the gene expression of NF- $\kappa \mathrm{B}$.

In conclusion, the $\mathrm{CDX} 2 / \mathrm{NF}-\kappa \mathrm{B}$ signaling pathway is an unusually structured network, by which CDX2 inhibits the growth of MGC-803 cells in vivo. This may explain an important aspect of the mechanism by which the overexpression of CDX2 contributes to the suppression of gastric cancer cell growth.

\section{Acknowledgements}

The present study was supported by grants from the National Natural Science Foundation of China (grant nos. 30860273 and 81060201, the Natural Science Foundation of Guangxi (grant nos. 2011GXNSFA018273 and 2013GXNSFAA019163 and the Key Health Science Project of Guangxi (grant no. Key1298003-2-6).

\section{References}

1. Chong VH, Telisinghe PU, Abdullah MS and Chong CF: Gastric cancer in Brunei Darussalam: epidemiological trend over a 27 year period (1986-2012). Asian Pac J Cancer Prev 15: 7281 7285, 2014.

2. Orditura M, Galizia G, Sforza V, et al: Treatment of gastric cancer. World J Gastroenterol 20: 1635-1649, 2014.

3. Duprey P, Chowdhury K, Dressler GR, Balling R, Simon D, Guenet JL and Gruss P: A mouse gene homologous to the Drosophila gene caudal is expressed in epithelial cells from the embryonic intestine. Genes Dev 2 (12A): 1647-1654, 1988.

4. Drummond F, Putt W, Fox M and Edwards YH: Cloning and chromosome assignment of the human CDX2 gene. Ann Hum Genet 61: 393-400, 1997.

5. Yuasa Y: Control of gut differentiation and intestinal-type gastric carcinogenesis. Nat Rev Cancer 3: 592-600, 2003.

6. Bai YQ, Yamamoto H, Akiyama Y, et al: Ectopic expression of homeodomain protein CDX2 in intestinal metaplasia and carcinomas of the stomach. Cancer Lett 176: 47-55, 2002.

7. Xiao ZY, Ru Y, Sun JT, Gao SG, Wang YF, Wang LD and Feng XS: Expression of CDX2 and villin in gastric cardiac intestinal metaplasia and the relation with gastric cardiac carcinogenesis. Asian Pac J Cancer Prev 13: 247-250, 2012.

8. Qin R, Wang NN, Chu J and Wang X: Expression and significance of homeodomain protein $\mathrm{Cdx} 2$ in gastric carcinoma and precancerous lesions. World J Gastroenterol 18: 3296-3302, 2012.

9. Kang JM, Lee BH, Kim N, Lee HS, Lee HE, Park JH, Kim JS, Jung $\mathrm{HC}$ and Song IS: CDX1 and CDX2 expression in intestinal metaplasia, dysplasia and gastric cancer. J Korean Med Sci 26: 647-653, 2011.

10. Zhang JF, Zhang JG, Kuai XL, Zhang H, Jiang W, Ding WF, Li ZL, Zhu HJ and Mao ZB: Reactivation of the homeotic tumor suppressor gene CDX2 by 5-aza-2'-deoxycytidine-induced demethylation inhibits cell proliferation and induces caspase-independent apoptosis in gastric cancer cells. Exp Ther Med 5: 735-741, 2013.

11. Xie Y, Li L, Wang X, Qin Y, Qian Q, Yuan X and Xiao Q: Overexpression of $\mathrm{Cdx} 2$ inhibits progression of gastric cancer in vitro. Int J Oncol 36: 509-516, 2010.

12. Li QL, Yang ZL, Liu JQ and Miao XY: Expression of CDX2 and hepatocyte antigen in benign and malignant lesions of gallbladder and its correlation with histopathologic type and clinical outcome. Pathol Oncol Res 17: 561-568, 2011.

13. Ikarashi S, Nishikura K, Ajioka Y and Aoyagi Y: Re-evaluation of phenotypic expression in undifferentiated-type early gastric adenocarcinomas using mucin core protein and CDX2. Gastric Cancer 16: 208-219, 2013.

14. Gross I, Duluc I, Benameur T, Calon A, Martin E, Brabletz T, Kedinger M, Domon-Dell C and Freund JN: The intestine-specific homeobox gene $\mathrm{Cdx} 2$ decreases mobility and antagonizes dissemination of colon cancer cells. Oncogene 27: 107-115, 2008.

15. Park Y, Srivastava A, Kim GH, Mino-Kenudson M, Deshpande V, Zukerberg LR, Song GA and Lauwers GY: CDX2 expression in the intestinal-type gastric epithelial neoplasia: Frequency and significance. Mod Pathol 23: 54-61, 2010.

16. Chang YT, Hsu C, Jeng YM, Chang MC, Wei SC and Wong JM: Expression of the caudal-type homeodomain transcription factor CDX2 is related to clinical outcome in biliary tract carcinoma. J Gastroenterol Hepatol 22: 389-394, 2007.

17. Huang LP, Yu YH, Sheng C and Wang SH: Up-regulation of cadherin 17 and down-regulation of homeodomain protein CDX2 correlate with tumor progression and unfavorable prognosis in epithelial ovarian cancer. Int J Gynecol Cancer 22: 1170-1176, 2012.

18. Wang XT, Wei WY, Kong FB, Lian C, Luo W, Xiao Q and Xie YB: Prognostic significance of $\mathrm{Cdx} 2$ immunohistochemical expression in gastric cancer: A meta-analysis of published literatures. J Exp Clin Cancer Res 31: 98, 2012. 
19. Shirali S, Aghaei M, Shabani M, Fathi M, Sohrabi M and Moeinifard M: Adenosine induces cell cycle arrest and apoptosis via cyclinD1/Cdk4 and $\mathrm{Bcl}-2 / \mathrm{Bax}$ pathways in human ovarian cancer cell line OVCAR-3. Tumour Biol 34: 1085-1095, 2013.

20. Tian YF, Chen TJ, Lin CY, et al: SKP2 overexpression is associated with a poor prognosis of rectal cancer treated with chemoradiotherapy and represents a therapeutic target with high potential. Tumour Biol 34: 1107-1117, 2013

21. Zhang X, Bi L, Ye Y and Chen J: Formononetin induces apoptosis in PC-3 prostate cancer cells through enhancing the Bax/Bcl-2 ratios and regulating the p38/Akt pathway. Nutr Cancer 66: 656-661, 2014.

22. Liu X, Yu H, Cai H and Wang Y: Expression of CD24, p21, p53, and c-myc in alpha-fetoprotein-producing gastric cancer: Correlation with clinicopathologic characteristics and survival. J Surg Oncol 109: 859-864, 2014.

23. Takahashi K, Hirano F, Matsumoto K, Aso K and Haneda M: Homeobox gene CDX2 inhibits human pancreatic cancer cell proliferation by down-regulating cyclin D1 transcriptional activity. Pancreas 38: 49-57, 2009.

24. Yang Z, Li C, Wang X, et al: Dauricine induces apoptosis, inhibits proliferation and invasion through inhibiting NF-kappaB signaling pathway in colon cancer cells. J Cell Physiol 225: 266-275, 2010.

25. Saha A, Blando J, Silver E, Beltran L, Sessler J and Digiovanni J: 6-Shogaol from dried ginger inhibits growth of prostate cancer cells both in vitro and in vivo through inhibition of STAT3 and NF-kappaB Signaling. Cancer Prev Res (Phila) 7: 627, 2014.

26. Barré $B$ and Perkins ND: A cell cycle regulatory network controlling NF-kappaB subunit activity and function. EMBO J 26 : 4841-4855, 2007

27. Kannaiyan R, Hay HS, Rajendran P, et al: Celastrol inhibits proliferation and induces chemosensitization through down-regulation of NF- $\kappa \mathrm{B}$ and STAT3 regulated gene products in multiple myeloma cells. Br J Pharmacol 164: 1506-1521, 2011.

28. Barrezueta LF, Oshima CT, Lima FO, De Oliveira Costa H, Gomes TS, Neto RA and De Franco MF: The intrinsic apoptotic signaling pathway in gastric adenocarcinomas of Brazilian patients: Immunoexpression of the Bcl-2 family (Bcl-2, Bcl-x, Bak, Bax, Bad) determined by tissue microarray analysis. Mol Med Rep 3: 261-267, 2010.
29. Roset R, Ortet L and Gil-Gomez G: Role of Bcl-2 family members on apoptosis: What we have learned from knock-out mice. Front Biosci 12: 4722-4730, 2007.

30. Jiang H, Zhao PJ, Su D, Feng J and Ma SL: Paris saponin I induces apoptosis via increasing the $\mathrm{Bax} / \mathrm{Bcl}-2$ ratio and caspase-3 expression in gefitinib-resistant non-small cell lung cancer in vitro and in vivo. Mol Med Rep 9: 2265-2272, 2014.

31. Kuo HC, Kuo WH, Lee YJ, Lin WL, Chou FP and Tseng TH: Inhibitory effect of caffeic acid phenethyl ester on the growth of C6 glioma cells in vitro and in vivo. Cancer Lett 234: 199-208, 2006.

32. Leu WJ, Chang HS, Chan SH, Hsu JL, Yu CC, Hsu LC, Chen IS and Guh JH: Reevesioside A, a cardenolide glycoside, induces anticancer activity against human hormone-refractory prostate cancers through suppression of c-myc expression and induction of G1 arrest of the cell cycle. PLoS ONE 9: e87323, 2014.

33. Castagnino P, Kothapalli D, Hawthorne EA, Liu SL, Xu T, Rao S, Yung Y and Assoian RK: miR-221/222 compensates for Skp2-mediated p27 degradation and is a primary target of cell cycle regulation by prostacyclin and cAMP. PLOS ONE 8: e56140, 2013.

34. Osawa T, Atsumi Y, Sugihara E, Saya H, Kanno M, Tashiro F, Masutani M and Yoshioka K: Arf and p53 act as guardians of a quiescent cellular state by protecting against immortalization of cells with stable genomes. Biochem Biophys Res Commun 432: 34-39, 2013.

35. Choi JK, Kim KH, Park SR and Choi BH: Granulocyte macrophage colony-stimulating factor shows anti-apoptotic activity via the PI3K-NF- $\mathrm{B}$-HIF- $1 \alpha$-survivin pathway in mouse neural progenitor cells. Mol Neurobiol 49: 724-733, 2014.

36. Lee KH, Choi EY, Koh SA, et al: Down-regulation of survivin suppresses uro-plasminogen activator through transcription factor JunB. Exp Mol Med 43: 501-509, 2011.

37. Szafer-Glusman E, Fuller MT and Giansanti MG: Role of Survivin in cytokinesis revealed by a separation-of-function allele. Mol Biol Cell 22: 3779-3790, 2011.

38. Götz J, David D, Hoerndli F, et al: Functional genomics dissects pathomechanisms in tauopathies: Mitosis failure and unfolded protein response. Neurodegener Dis 5: 179-181, 2008. 